Mediscope

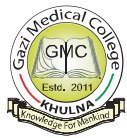

The Journal of GMC

ORIGINAL ARTICLE

\title{
Ultrasonographic evaluation of portal hypertnsion
}

\author{
MS Ahmed ${ }^{1}$, PK Chowdhury², AS Mohiuddin ${ }^{3}$, MA Hossain ${ }^{4}$, B Paik ${ }^{5}$
}

\begin{abstract}
A descriptive type of cross-sectional study was done to measure diameters of splenic, superior mesenteric and portal veins with their variation with respiration in patients with portal hypertension. Trans-abdominal ultrasonography was used for the purpose among purposively selected 59 patients with chronic liver disease and portal hypertension using computer sonography with multiple probes having multiple frequency depending on physical built of subjects. The diameters of selected veins were measured in the course of expiration and deep inspiration. Mean age of respondents was 53.2 years with standard deviation of 11.4 years. 44 (74.6\%) subjects were male, whereas 15 (25.4\%) were female. In all cases oesophageal varices were present. Portal vein was clearly visualized in all cases, while splenic vein in 53 $(89.8 \%)$ cases and superior mesenteric vein in $49(83.1 \%)$ cases. During deep inspiration, diameter of portal vein was greater than $13 \mathrm{~mm}$ in $31(52.5 \%)$, while $\leq 13 \mathrm{~mm}$ in $28(47.5 \%)$ of portal hypertensive cases. Of 31, lack variation in diameter during respiration was observed in $29(93.6 \%)$ cases. Size of liver (length in mid-clavicular line) in $18(30.5 \%)$ cases were between 96 to $115 \mathrm{~mm}$, while in $19(32.2 \%)$ cases it was within 116 to $135 \mathrm{~mm}$ and in $22(37.3 \%)$ cases it was between 136 to $160 \mathrm{~mm}$. In $36(61.0 \%)$ cases surface of liver was irregular, while in 51 $(86.4 \%)$ cases parenchymal echotexture of liver was coarse. Size of spleen was enlarged in 44 $(74.6 \%)$ cases, and ascites was present in 47 (79.7\%) cases. Diameter variation with breathing of splenic and superior mesenteric veins observed only in 5 (8.5\%) patients. Lack of diameter variation of portal, splenic and superior mesenteric veins with respiration in ultrasonography is an indicator of portal hypertension.
\end{abstract}

Key Words: Ultrasonographic evaluation of portal hypertnsion

\section{Introduction}

Pathological increase in portal venous pressure with the formation of porto-systemic collaterals that divert portal blood to the systemic circulation, by passing the liver, clinically known as portal hypertension. ${ }^{1}$ Liver cirrhosis is the dominant intrahepatic cause of portal hypertension. ${ }^{2}$ Primarily, portal hypertension in cirrhosis of liver is due to increased resistance to portal flow at the level of hepatic sinusoid due to narrowing of the sinusoidal channels by perisinusoidal deposition of collagen, and compression of central veins by perivenular fibrosis and expansile parenchymal nodules. Worldwide,

1. MS Ahamed, Associate Prof. (cc) of Radiology \& Imaging, Kushtia Medical College, Kushtia Email: dr.saadahmedbd@gmail.com

2. PK Chowdhury, Assistant Professor of Respiratory Medicine, Khulna Medical College, Khulna

3. AS Mohiuddin, Professor of Radiology \& Imaging, and Senior Consultant, BIRDEM, Dhaka

4. MA Hossain, Professor of Radiology \& Imaging, Rangpur Medical College, Rangpur

5. B Paik, Associate Professor of Gastroenterology, Khulna Medical College, Khulna 
the most common causes of cirrhosis are chronic viral hepatitis and prolonged excessive alcohol consumption. ${ }^{3}$ In Bangladesh, viral hepatitis is the commonest cause of chronic hepatitis. Portal hypertension can be classified into presinusoidal (extrahepatic and intrahepatic), sinusoidal (intrahepatic) and post-sinusoidal (intrahepatic and extrahepatic) on the basis of the principal sites of obstruction to blood flow in the portal venous system. Despite all possible causes, portal hypertension indicates cirrhosis until proved otherwise. ${ }^{2}$ Major clinical consequences of portal hypertension are formation of portosystemic venous shunts, ascites, congestive splenomegaly and occasionally hepatic encephalopathy. ${ }^{2}$ At least 30 to 70 per cent of the patients of liver cirrhosis with portal hypertension develop oesophageal varices. Bleeding from ruptured oesophageal varices is one of the serious complications with case fatality rate of 20 to 50 per cent. ${ }^{4-6}$

The most important symptoms of liver cirrhosis are haemmorrhage from oesophageal varices and ascites due to circulatory alterations at the portal venous system. It is important to get information about portal venous system with the aim of discovering portal hypertension in patients with asymptomatic chronic hepatic lesion. ${ }^{7}$ As a rule, oesophagoscopy and barium examination of the oesophagus are commonly carried out to detect oesophageal varices. However, this is sufficient to establish the presence of portal hypertension but not its cause(s). As these examinations obviously fail to provide information regarding morphology of main portal vessels. Portal venography demonstrates the site and often the cause of portal venous obstruction which is performed prior to surgical intervention. Arterio-portography and contrast enhanced spiral CT may be used for evaluating extra-hepatic portal problem. Hepatic venography can be diagnostic for post-hepatic portal hypertension. Portal venous pressure measurements rarely needed but can be carried out for confirmation of portal hypertension. All these methods bear some degree of risk and generally encounter a certain unwillingness on the part of the patients.

The study was aimed to measure the diameters of splenic, superior mesenteric and portal veins with their variation with respiration in patients with portal hypertension that would help in detecting the cases with portal hypertension.

\section{Materials and Method}

A descriptive type of cross-sectional study was carried out among purposively selected 59 study subjects with chronic hepatic disease with portal hypertension. Study subjects were selected from in-patient and out-patient departments of BIRDEM. Study was conducted at Radiology and imaging department with active co-operation of department of gastrointestinal, hepatobiliary and pancreatic disorders (GHPD) of BIRDEM, Shahbag, Dhaka from July, 2011 to June, 2012.

All study subjects were evaluated by detailed history, relevant physical examinations and findings of laboratory tests and oesophagoscopic examination. Transabdominal ultrasonography of hepatobiliary system and spleen was carried out using Acuson computer sonography system with model $128 \times \mathrm{p} / 4$ multiple probes with multiple frequency, ranges from 2.5, 3.5, 4.5 and $7 \mathrm{MHz}$, Siemens Sonoline-II, with 3.5 and $5 \mathrm{MHz}$ probes, and Tosbee from Toshiba Company with $3.75 \mathrm{MHz}$ Transducer. Frequency chosen from $4 \mathrm{MHz}$ and $2.5 \mathrm{MHz}$ probes depending on physical built of the subjects. Before sonographic examinations, subjects were advised to have nothing by mouth for 6 to 8 hours preceding the examination. They were positioned supine, and portal, splenic and superior mesenteric veins were imaged ultra-sonographically. The portal vein was imaged in sagittal or right oblique scan at upper right epigastrium, while the splenic and superior mesenteric veins were imaged in transverse and sagittal scan at epigastrium, respectively. The diameters of portal, splenic and superior 
Table 1. Diameter of portal vein and its variation with respiration

\begin{tabular}{llll}
\hline Diameter of portal vein & \multicolumn{2}{l}{ Lack of diameter variation during respiration } & Total \\
\cline { 2 - 3 } & $\begin{array}{llll}\text { Present } \\
\mathrm{n}(\%)\end{array}$ & $\begin{array}{l}\text { Absent } \\
\mathrm{n}(\%)\end{array}$ & $\mathrm{n}(\%)$ \\
\hline$>13 \mathrm{~mm}$ & $29(93.6)$ & $2(6.5)$ & $31(100.0)$ \\
$\leq 13 \mathrm{~mm}$ & $19(67.9)$ & $9(32.1)$ & $28(100.0)$ \\
\hline Total & $48(81.4)$ & $11(18.6)$ & $59(100.0)$ \\
\hline
\end{tabular}

n, number

mesenteric veins were measured during breathing in the course of expiration and deep inspiration in particular. In each case, after the respiratory shift, the scanning plane was tilted until the maximum diameter of the vessels was detected. Liver and spleen were also scanned. Moreover, whole abdomen was scanned for ascites. Serological tests related to viral infection and viral markers were also conducted. Findings were compiled using master sheet and scientific calculator.

\section{Results}

Age of the patients was ranged from 22 to 78 years. Mean age of respondents was 53.2 years with standard deviation of 11.4 years. Of 59 respondents, $44(74.6 \%)$ were male and $15(25.4 \%)$ were female. Among patients with chronic liver disease with portal hypertension, it was observed in oesophagoscopic examination that in all cases oesophageal varices were present. With regard to grading of oesophageal varices, it was revealed that in 20 (33.9\%) cases it was grade-I, while in $24(40.7 \%)$ it was grade-II, in 11 (18.6\%) it was grade-III and in $4(6.8 \%)$ cases it was grade-IV. With respect to viral markers, it was observed that out of 59 , in $51(86.4 \%)$ cases serological test reports for viral markers were found, whereas in $8(13.6 \%)$ cases reports for viral markers were not found. Of 51, $26(51.0 \%)$ were positive for HBSAg, while 16 (31.4\%) were positive for Anti-HCV, 3 (5.9\%) were positive for Anti-HBC and 6 (11.8\%) were negative for all the viral markers.

Of 59 cases with portal hypertension, it was revealed that portal vein was clearly visualized in all cases, while splenic vein in $53(89.8 \%)$ cases and superior mesenteric vein in $49(83.1 \%)$ cases. It was revealed that during deep inspiration maximum diameter of portal, splenic and superior mesenteric veins were 9.2 to $17.0 \mathrm{~mm}, 6.4$ to $12.0 \mathrm{~mm}$ and 8.4 to $13.4 \mathrm{~mm}$ with mean diameters and standard deviation of $13.4 \pm 1.8 \mathrm{~mm}, 9.3 \pm$ $1.5 \mathrm{~mm}$ and $11.0 \pm 1.2 \mathrm{~mm}$, respectively. During deep inspiration, diameter of portal vein was $>13 \mathrm{~mm}$ in $31(52.5 \%)$, while $\leq 13$ $\mathrm{mm}$ in $28(47.5 \%)$ of portal hypertensive cases. Of 31 , lack of variation in diameter during respiration was observed in 29 $(93.6 \%)$ cases, while in $2(6.5 \%)$ cases it was not observed. Of 28 portal hypertensive cases with diameter of portal vein $\leq 13 \mathrm{~mm}$, $19(67.9 \%)$ had lack of diameter variation with respiration, whereas $9(32.1 \%)$ did not have lack of dilatation variation with respiration (Table 1). Among portal hypertensive subjects, in deep inspiration diameter of splenic vein in $18(30.5 \%)$ and superior mesenteric vein in $42(71.2 \%)$ cases were $>10 \mathrm{~mm}$. Patients with portal hypertension diameter variation with breathing at the level of splenic and superior mesenteric veins observed only in 5 (8.5\%) cases. Lack of variation in diameter in one the major tributaries of portal vein, splenic and mesenteric veins, during respiration was present in $48(81.4 \%)$ cases. Of 48 , in 44 $(91.7 \%)$ cases lack of variation in diameter was observed in both splenic and superior mesenteries veins, while in $4(8.3 \%)$ cases variation was observed only in splenic vein. In $6(12.5 \%)$ cases both splenic and mesenteric arteries were not visualized, while diameter variation with respiration was noted in 5 (10.4\%) cases. 


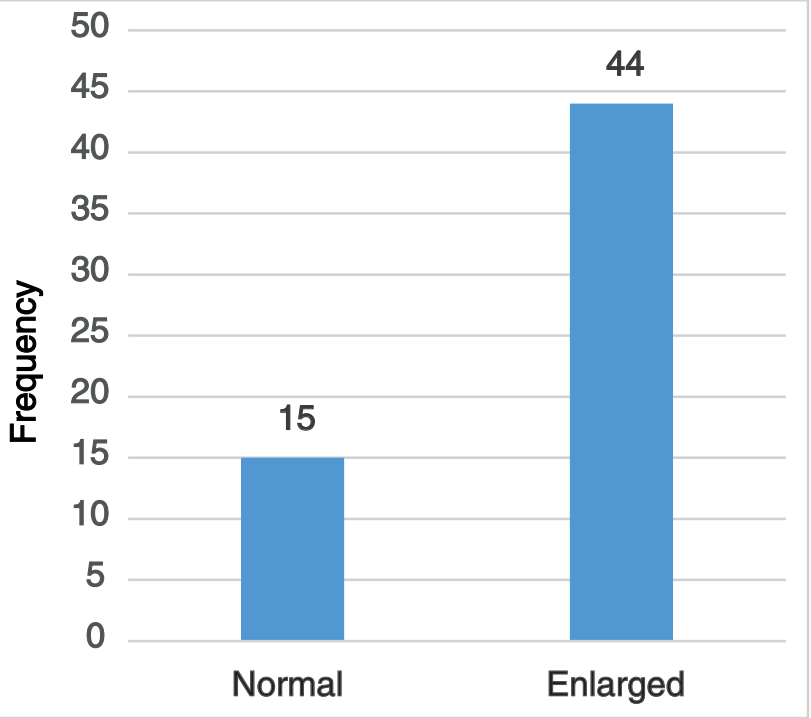

Fig. 1. Size of spleen in portal hypertension.

Besides measurement of diameter of portal vessels, ascites, liver and spleen were evaluated. Size (longitudinal measurement of liver in mid-clavicular line), surface regularity and parenchymal echo-texture of liver and size of spleen were also observed. It was observed that size of liver in 18 (30.5\%) cases were between 96 to $115 \mathrm{~mm}$, while in $19(32.2 \%)$ cases it was within 116 to 135 $\mathrm{mm}$ and in $22(37.3 \%)$ cases it was between 136 to $160 \mathrm{~mm}$. Regarding surface, it was revealed that in $36(61.0 \%)$ cases it was irregular, while in $23(39.0 \%)$ it was regular. With respect to parenchymal echo-texture in $51(86.4 \%)$ cases it was coarse, while in 8 $(13.6 \%)$ cases it was uniform. Among patients with chronic liver disease with portal hypertension size of spleen was normal in 15 (25.4\%) cases, while enlarged in 44 (74.6\%) cases (Fig. 1). Ascites was present in 47 $(79.7 \%)$, while absent in $12(20.3 \%)$ cases.

\section{Discussion}

A descriptive, cross-sectional study was conducted among 59 patients of chronic liver disease with portal hypertension to measure diameters of splenic, superior mesenteric and portal veins through trans-abdominal ultra-sonography. Moreover, size and surface of liver and spleen were also scanned with scanning of whole abdomen for ascites. Variation in diameters of aforementioned veins with respiration were estimated.
Of 59 subjects with portal hypertension, portal, splenic and superior mesenteric veins were visualized in 59 (100.0\%), 53 (89.8\%) and $49(83.1 \%)$ cases, respectively. The ultrasonographic nonvisualization of splenic and superior mesenteric veins in portal hypertensive subjects may be due to technically unsatisfactory scan as of gas in bowel obscuring the veins. Goyal et al in 1990 revealed that portal, splenic and superior mesenteric veins were displayed on ultrasound in $100.0 \%, 92.0 \%$ and $82.0 \%$ subjects with portal hypertension, respectively. ${ }^{8}$ This is more or less consistent with the present study findings. Slight variation may be due to small sample size and technically unsatisfactory scan.

Diameter of splenic and superior mesenteric veins remained unchanged or showed only slight variation, less than $10 \%$, in most 54 $(91.5 \%)$ of the cases with portal hypertension. This is supported by findings of study conducted by Kurol et al as increased pressure caused by descending diaphragm is not transmitted through non-elastic cirrhotic liver is the possible explanation of diminished respiratory variation. ${ }^{9}$

Patients with portal hypertension diameter variation with breathing at the level of splenic and superior mesenteric veins observed only in 5 (8.5\%) cases. In deep inspiration, maximum diameter of portal, splenic and superior mesenteric veins were 9.2 to $17.0 \mathrm{~mm}, 6.4$ to $12.0 \mathrm{~mm}$ and 8.4 to $13.4 \mathrm{~mm}$, respectively. The mean diameters and standard deviations of splenic and superior mesenteric veins were $9.29 \pm 1.53$ $\mathrm{mm}$ and $11.02 \pm 1.17 \mathrm{~mm}$, respectively. In deep inspiration, mean diameter and standard deviation of splenic and superior mesenteric veins were estimated $7.2 \pm 1.7$ $\mathrm{mm}$ and $9.0 \pm 1.9 \mathrm{~mm}$, respectively by Kurol et al and $8.4 \pm 1.3$ and $8.1 \pm 1.2 \mathrm{~mm}$, respectively by Goyal et al. 8,9

Among portal hypertensive subjects, in deep inspiration diameter of splenic vein in 18 $(30.5 \%)$ and superior mesenteric vein in 42 $(71.2 \%)$ cases were $>10 \mathrm{~mm}$. During deep 
inspiration, diameter of portal vein was $>13$ $\mathrm{mm}$ in 31 (52.5\%), while $\leq 13 \mathrm{~mm}$ in 28 $(47.5 \%)$ of portal hypertensive cases. In portal hypertensive cases it was revealed that during inspiration diameter of portal vein was 9.2 to $17.0 \mathrm{~mm}$ with a mean of $13.4 \mathrm{~mm}$ and standard deviation of $\pm 1.76 \mathrm{~mm}$. In 31 $(52.5 \%)$ portal hypertensive subjects diameter of portal vein was $>13.0 \mathrm{~mm}$. Kane et al in 1982, Weinreb et al and Al-Naksabandi in 2006 observed that in portal hypertension with haemo-dynamically effective porto-systemic shunts, the portal vein might remain small as much of the portal flow might be diverted through collaterals. ${ }^{10-12}$ Although there is wide discrepancies in the upper normal values in the portal vein diameter, Weinreb et al and Bolondi et al reported that a portal vein diameter $>13.0 \mathrm{~mm}$ is a fair characteristic sign of portal hypertension. ${ }^{7,11}$

\section{Conclusion}

Based on the study findings it can be concluded that trans-abdominal ultrasonography plays a significant role in assessment of portal hypertension by observing lack of diameter variations of splenic, superior mesenteric and portal veins with respiration.

\section{References}

1. Bosch J, Pizcueta P, Feu F, Fernendez M, Pagan JCG. Pathophysiology of Portal Hypertension. Gastroenterology Clinics of North America 1992;21(1):1-14.

2. Crawford JM. and Liu C. Liver and the Biliary Tract, In: Robbins and Cortan. Pathologic Basis of Disease, $8^{\text {th }}$ Edition, Kumar V, Abbas AK, Fausto N, Aster JC (Editors). Saunders Elsevier: Philadelphia, USA, 2010:p.838.

3. Collier JD and Webster G. Liver and Biliary Tract Disease. In: Davidsons
Principles and Practice of Medicine. $21^{\text {st }}$ Edition. Colledge NR, Walker BR, Ralston $\mathrm{SH}$ (Editors). Churchill Livingstone: London, 2010:p.942.

4. Kishimoto $R$, Chen $M$, Ogawa $H$, Wakabayashi MN, Kogutt M. Oesophageal Varices: Evaluation with Transabdominal Ultrasonography. Radiology 1998;206:647-50.

5. Franchis $R$, Priorignami M. Natural history of portal hypertension with cirrhosis. Clinical Liver Disease 2001; 5:645-65.

6. Garcia-Tsao G, Groszmann RH, Fischer $\mathrm{RL}$, Conn HO, Atterbury CE, Glickman M. Portal pressure, presence of gastrointestinal varices and variceal bleeding. Hepatology, 2003;31:1061-7.

7. Bolondi I, Gandolfi L, Arienti V, et al. Ultrasonography in the diagnosis of portal hypertension: diminished response of portal vessels to respiration. Radiology 1982;142:167-72.

8. Goyal AK, Pokharna DS, Sharma SK. Ultrasonic measurement of portal vasculature in diagnosis of portal hypertension. $\mathrm{J}$ Ultrasound Med 1990;9:45-8.

9. Kurol $M$ and Forsberg L. Ultrasonographic investigation of respiratory influence on diameters of portal vessels in normal subjects. Acta Radiological Diagnosis 1986;27:675-80.

10. Kane RA, Katz SG. The spectrum of sonographic finding in portal hypertension: a subject review and new observations. Radiology 1982;142:453-8.

11. Weinreb J, Kumari S, Philips G, Pochaczevsky R. Portal vein measurements by real time sonography, Am J of Radiol 1982;139:497-9.

12. Al-Nakshabandi NA. The role of ultrasonography in portal hypertension. Saudi J Gastroenterol 2006;12(3): 111-7.

\section{Suggestion for citation of the above:}

Ahmed MS, Chowdhury PK, Mohiuddin AS, Hossain MA, Paik B. Ultrasonographic evaluation of portal hypertnsion. Mediscope 2015;2(1):27-31. 